is, sixty-six days ; but if these small spots be considered we find an interval of twenty-five days without spots-namely, from April II to May 5. The minimum period, therefore, appears to have passed about the end of April, this being the time when the greatest number of days passed without spots being observed on the sun. The new period opened with the appearance of a large spot on June 16.

RETURN OF BRORSEN's COMET. - The following elements and ephemeris for this comet are given by Dr. E. Lamp in Astronomische Nachrichten, No. 2933 :--

$$
\begin{aligned}
& \mathrm{T}=\mathbf{I} 890 \text { February } 24^{\circ} \mathbf{3} 38 \text { Berlin midnight. } \\
& \omega=\quad \stackrel{\circ}{14} 55^{\prime \prime} 35^{\prime \prime} \cdot 89 \text { ) } \\
& \left.\Omega=\text { IOI } 2733^{\circ} 74\right\} \text { Mean Eq. } 1890^{\circ} 0 \\
& \iota=292348 \cdot 25 \\
& \phi=54.746 \cdot 19 \\
& \mu=650^{\prime \prime} \cdot 3693 \\
& \text { Ephemeris for Berlin Midnight. }
\end{aligned}
$$

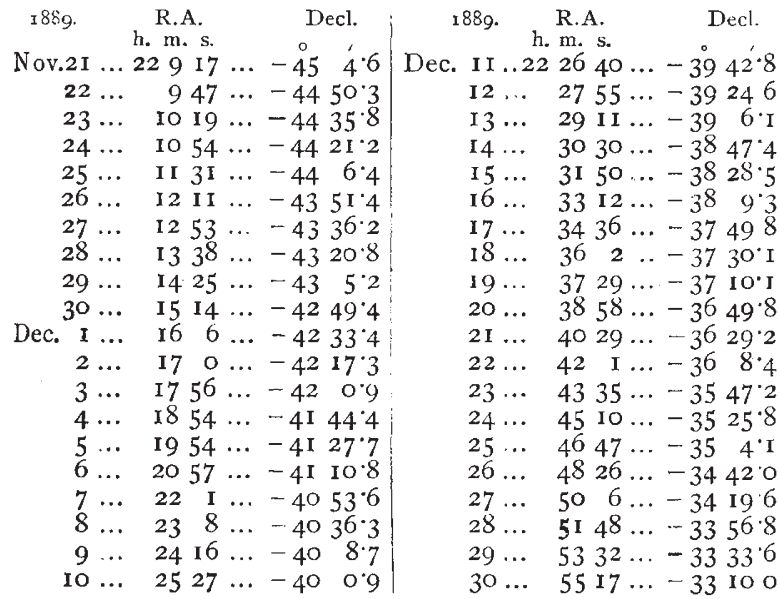

The Companion of $\eta$ Pegasi- - A companion to $\eta$ Pegasi was discovered by Sir William Herschel in 1780 , and subsequently observed by South in I824. Its magnitude has been rated from twelve to fifteen. Mr. S. W. Burnham, however, notes (Astronomische Nachrichten, No. 2933) that, using the 36 -inch refractor at the Lick Observatory, the Herschel companion appears as a close double. South's mean of two measures is given in his catalogue as:-

$$
1824 \cdot 84 \quad 33^{\circ} \cdot 9 \quad 89^{\prime \prime} \cdot 82 \quad 2 n \mathrm{~S} .
$$

The following is the mean of four measures made at Mount Hamilton :-

$$
\mathrm{B} \text { and } \mathrm{C} . \quad \eta \text { Pegasi. } \quad \mathrm{A} \text { and } \mathrm{BC} \text {. }
$$

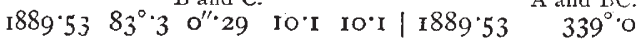
The close pair is difficult, and can hardly fail to be a physical system, and Mr. Burnham thinks that, although it is not a test for the large telescope, it will not be seen with any small instrument.

General Bibliography of Astronomy.--The second part of Vol. I. of this comprehensive bibliography has been pub lished. It represents Houzeau's last work, and hence it is well that his biographical note, by A. Lancaster, should be included. The first part of Vol. I., published in 1887 , contained the references to historical works and those relating to astrology the part just published contains the references to biographies of astronomers and their epistolary communications, general astronomical works, astronomical societies and their proceedings, and everything relating to spherical astronomy. Works on theoretical astronomy are also well represented. The third and last part of Vol. I. is now in press, and contains references to all the published matter on the mechanism of the heavens, physical, practical, and descriptive astronomy, and the systems of cosmogony. The utility of this bibliography, when completed, needs no comment.

J. C. Houzeau's "VAde Mecum."-With reference to our biographical note on J. C. Houzeau (p. 20), M. A. Lancaster writes to remind us that Houzeau's "Vade Mecum" was issued after the appearance of the second volume of the "Bibliographie Générale de l'Astronomie," the publication of which began in 1879. Moreover, the "Vade Mecum" was only a second edition of the "Répertoire des Constantes de l'Astronomie," inserted in 1877 in the first volume of the new series of the "Annales Astronomiques" of the Brussels Royal Observatory. The numerous materials brought together for the "Bibliographie Générale" suggested to Houzeau the idea of issuing a new edition of the "Répertoire" considerably corrected and enlarged.

A New Comet. - A new comet was discovered on Novem ber 17 by Mr. Lew is Swift, of the Warner Observatory, Roches ter, New York. Place at November 17,6h. $35 \mathrm{~m}$. 2s. G. M. T.; R.A. $=22 \mathrm{~h} .42 \mathrm{~m} \cdot 24 \mathrm{~s}$. ; N.P.D. $=78^{\circ} 9^{\prime}$. Daily motion in R.A., +2 m. ; in N.P.D., $-15^{\prime}$. The comet was only faint.

\section{MIRAGE IN THE SOUTH AMERICAN PAMPAS.}

WAS staying in the Pampas of the Argentine Republic, near

Melincue, a small town of the Province of Santa Fe, from September 1888 to March I889. During my stay I had the opportunity of observing certain mirage phenomena. It is possible that my notes may contain something of interest. They were, designedly, taken without reference to any previous knowledge of the theory of mirage that I might possess.

To illustrate my observations I had drawn eight diagrams; but, for the purpose of insertion in NATURE, I have been obliged to reduce these to two. Hence I fear that my descrip. tions may not be as clear as I should wish.

The most general conclusion at which I arrived was that there were two classes of mirage of very different character. The one I shall call "the summer mirage," the other "the winter mirage." I would observe that, without a telescope of some sort, one would be unable to make observations of much value; and that, as I had but a binocular telescope, in many details I failed to make out as much as I could had I possessed a larger telescope steadily mounted.

\section{The Summer Mirage.}

(I) This mirage is seen in full day. I was told that in normal years it is most remarkable in the extreme heat of summer. The summer of December, January, and February I 888 and I889 was abnormally wet, however. And I myself saw the mirage most frequently in spring (September, Octoher, and the earlier part of November), the grass being then short and very dry. Later on the grass became very long, and unusually green and damp, owing to the heavy rains. And then I saw the mirage but rarely in the grass plains, though on the several occasions on which I passed, in the blaze of a summer day, the dry sandy bed of an old laguna, the mirage was there to be seen very clearly.

On one or two occasions in spring I saw the mirage when there was a fairly cold wind and no perceptible sunshine, but still in full day.

(2) This kind of mirage usually appeared as a strip of "water" running more or less parallel to the horizon, at one end narrowing to a point, and at the other end opening out into the sky. It appeared much as an arm of the sea, or an estuary, seen near the horizon, and running parallel to it. The "water" was of the same colour as the sky above it near the horizon.

(3) Viewed through glasses, the whole of the land seen above and beyond the "water," the "water" it:elf, and to a less extent the land seen just this side of it, appeared wavy and illdefined, flocculent, and (when there was any breeze) possessed of a drifting movement down the wind. At the thin end of the "water," and just beyond it in the line of the layer, one could see broken fragments of "water" drifting over the land; and, in like manner, the peninsula of land appeared to end in a line of drifting fragments.

(4) It appeared to me that the land seen beyond the watery layer was either within the limits of the natural horizon, or not much beyond them. One did not, as one did in the "winter mirage," see houses, \&c., that were normally out of sight.

(5) Cattle, \&c., seen in the watery layer were ill-defined. But on the whole it seemed that their legs were hidden, and bodies were reflected inverted, much as if they had been standing in shallow water. 
(6) When I mounted highcr, a mirage, if seen at all, was further off than when I stood lower.

If, when looking at the watery layer of a mirage, I mounted higher, the "water" narrowed, and the strip of land beyond it widened, until at a certain height of my head the "water" had narrowed into a wavy line of fragments. Further mounting caused the "water" to disappear. If, on the contrary, I stooped, the "water" appeared to widen, the strip of land above it to narrow, until at last the mirage joined the sky.

On one occasion, when the mirage was about a mile and a half distant, and on another occasion when about $25^{\circ}$ yards distant, I caused the "water" to appear and disappear by a vertical movement of my head not exceeding I foot.
(7) Objects situated in the watery layer but rising out of it or on the strip of land beyond it, were reflected in the "water" much as in true water; but all was ill-defined, and the inverted reflections often broken and lengthened.

(8) It appeared to me that objects on the strip of land beyond the watery layer were also to be seen faintly reflected in the land that lay between them and the "water." And when, as in (6), I had raised my head until the "water" had just dwindled away, objects near the horizon were reflected inverted in the region from which "water" had vanished.

(9) By the aid of my glasses I came to the conclusion that objects were not really, as they appeared to the naked eye, "drawn up" by the mirage. But it seemed rather that, an

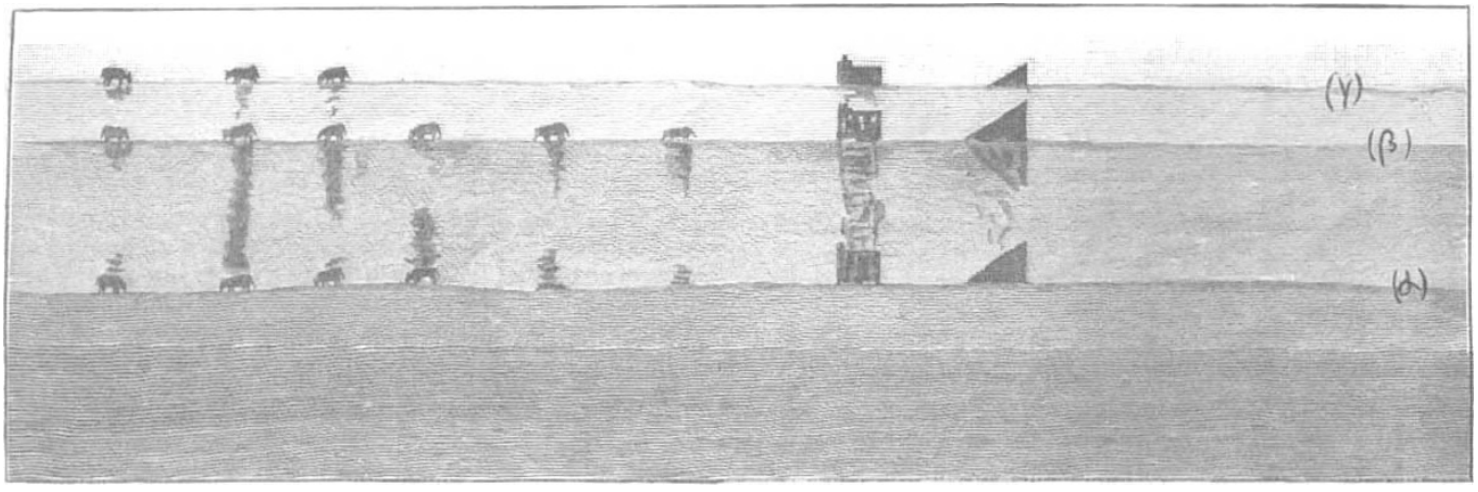

FIG. I.

object being seen above its (often elongated) reflected image, and both being ill-defined, to the naked eye the whole appeared like the object "drawn up." In this way clumps of grass appeared as trees.

(10) In (I) I have mentioned the usual form of the mirage. But with various slopes, \&c., of the ground, the form of the mirage varied. Sometimes the "water" opened out into the sky both ways; and several times I saw an isolated patch of "water" over an isolated patch of bare hot earth.

Conclusions as to Summer Mirage.-It seemed, then-

(1) That this mirage was due to a layer of relatively warm air close to the earth.

(2) That this mirage-giving layer was not more than about feet in depth, and that it may have been less.
(3) That there were not, to any noticeable extent, vertical elongations of objects nor extensions of normal horizon.

(4) That in this mirage there were no images, erect or inverted, seen above the real object.

In fact, it seemed that the sky and terrestrial objects were simply reflected in a sheet of warmer air lying close to the ground. (Of course the paths of the rays would be curved.)

\section{The Winter Mirage.}

[I was told that this mirage is seen in winter, and best on fine mornings after hard frost. What I saw were, it seemed, but poor specimens.]

(I) I saw this mirage several times, always about sunrise and after a frost. Before sunrise, as soon as there was any light, I

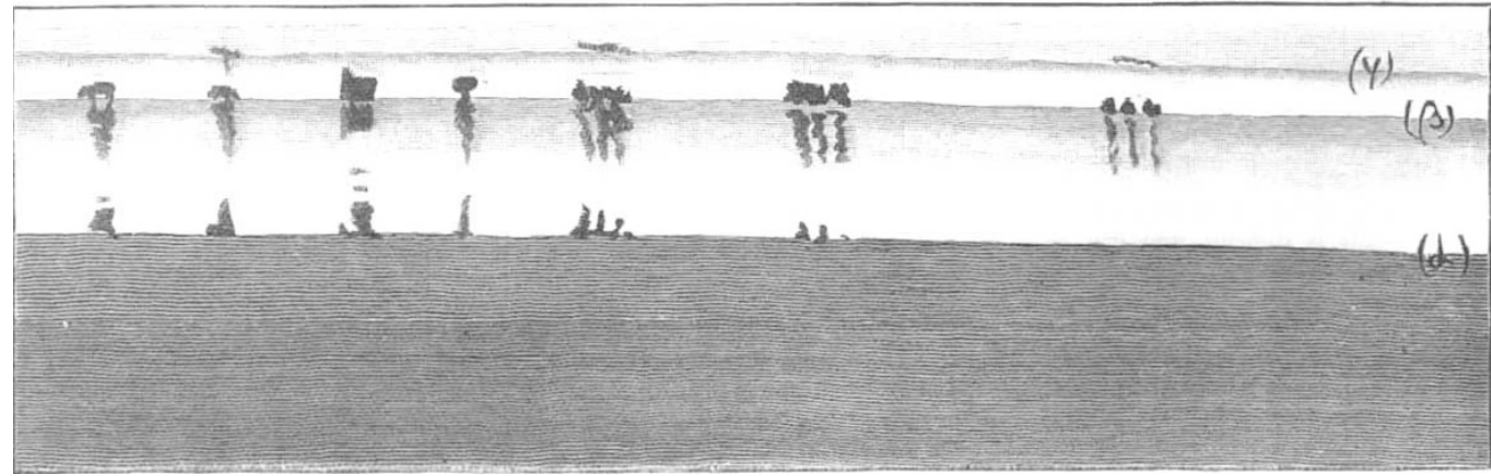

F1G. 2.

looked out into the plains with my binoculars. It appeared as if the horizon were higher than usual, and that one could see tracts of land, with houses and other objects, that were usually concealed below the horizon.

Further, it seemed that this extension of horizon was not really continuous, as it at first appeared, but that it was divided into layers. As far as I could judge, the line (a) was beyond the normal limits of the horizon, the tract from $(\alpha)$ to the limit $(\boldsymbol{\beta})$ was more or less a repetition of the tract below $(\alpha)$, and from $(\beta)$ to $(\gamma)$ was again more or less a repetition of the same tract. As to what one could see above the line $(\gamma)$, I could make no trustworthy observations.

Before sunrise, this extension of the horizon was seen all round; and, though the layers referred to could be distinguished fairly well, there were as yet no "watery layers" to be seen.

The land seen just above the lines $(\alpha)$ and $(B)$ was paler than that seen just below these lines.

(2) Thanks to a most convenient distribution of cattle of various colours, and of other objects, I was able, with the aid of my glasses, to make out a good deal.

But the images changed as the cows moved, the appearances varied as time went on, and were so different in different parts of the horizon, that I could only arrive at some general conclusions.

There would be, for example, just below, or on the edge of, the line $(a)$, a cow. This I will call the "furst cow", or the 
"original cow." Just below or on the line $(\beta)$, vertically above the first cow, and, like it, erect, would be a second cow, a repetition of the first. And often, above this again, below or on the line $(\gamma)$, would be a third cow, also erect.

Sometimes there were confused images hanging from the second cow and joining other confused images piled on the first cow ; sometimes the first cow was clear of images, while they hung down from the second cow; sometimes the second cow was clear, and there were images piled on the first. Often the third cow was missing (see Fig. $x$ ). As the original cow moved, these images changed their disposition or vanished, and the third cow appeared or vanished. But in all these changes it seemed to me that the first cow, second cow, and (when visible) the third cow, were the permanent images. These, it appeared, were always erect.

(3) After the sun had risen, all continued in statu quo for a short time. But soon, at various parts of the horizon, the land just above the edges $(\alpha),(\beta)$, and $(\gamma)$ paled away, and finally meited into the appearance of "sky" or "water." There were left, in the later stages of the mirage, first, the plain itself, with an extension, the limits of which were not sharp, beyond the normal horizon ; secondly, above this a strip of land, apparently suspended in the air; thirdly, in some parts of the horizon another strip of land suspended in the air above this again. The interval between $(\alpha)$ and $(\beta)$ was in all stages greater than that between $(\beta)$ and $(\gamma)$. One of the appearances in the later stages is indicated in Fig. 2.

Other changes crept in, too. Very often the original objects were wholly or partly sunk out of sight; the images were less defined; and the confused images hanging from the second cow, e.g., or piled on the first cow, were now seen in the watery layers, sometimes bridging it over.

(4) As time went on, the watery layers widened. The images, too, became still vaguer, and the original objects were usually ont of sight or only just indicated above the line $(\alpha)$. Moreover, the aërial images, with their confused trails of images hanging from them, began to assume more the appearance of "inverted images suspended over objects hidden below the horizon."

(5) In these later stages, no doubt, anyone would have guessed that the aërial images were indeed very vaguely defined invertect images. But to me, as I followed the phenomenon from the beginning, it seemed that they were not so. It seemed to me that each aërial image was really topped by an erect image, which, with the trails hanging from it, seemed like an inverted image. At least I can say that, so long as the images were well defined at all, I never made out a clear case of the main, or permanent, aërial images being inverted. Thus, as the first cow moved, it was the erect second (and sometimes third) cows that remained clear.

(6) In these later stages it was only trees and houses that could be seen in the mirage, and these were ill-defined.

(7) The mirage lasted until about an hour and a quarter after sunrise. The last traces of aërial images of land appeared just under the sun, and in that part of the horizon that lay just opposite to it. Whether the abnormal extension of the horizon entirely ceased at the same time, I cannot say; but there did not remain any noticeable extension

(8) As with the summer mirage, I found I could alter appearances by altering my level above the earth. But the change in level had to be more considerable. I have no good notes on this matter; but I believe that usually I could recover a past stage of the mirage by a sufficient descent down a ladder from my post of observation.

General Conclusions as to Winter Mirage :-

I) It is due to the earth, and the air near it, being considerably chilled below the temperature of the rest of the atmosphere.

(2) The phenomena of extended horizon and multiple images are to be observed.

(3) The "drawn up" appearance of objects is really due to a number of images piled upon one another, only to be separated by the use of a telescope.

(4) No case of a terrestrial object having above it a single inverted image, or images of which the uppermost was inverted, came under my notice.

W. LARDEN.

SCIENTIFIC SERIALS

American Tournal of Mathematics, vol. xii. No. I, and index to vols. i.-x. (Baltimore, I889). -This volume opens with an instalment of sixty pages of a memoir by A. R. Forsyth, F.R.S., on "Systems of Ternariants that are Algebraically Complete." In this the writer has found it convenient to use " "ternariant" as a generic term for concomitants of ternary quantics, instead of giving it the signification which Prof. Sylvester proposed (Amer.J. of Math., vol. v. p. 8I) to give to it, viz. the leading coefficients of those concomitants." The memoir is divided into three parts, and deals with the theory of the algebraically independent concomitants of ternary quantics, taking as the starting-point the six linear partial differential equations of the first order satisfied by them. References are supplied to numerous memoirs on the subject.-Captain (now Major) P. A. Macmahon continues (pp. 6I-102) his investigations (vol. xi. No, I) in a "Second Memoir on a New Theory of Symmetric Functions." Herein he is engaged with functions which are not necessarily integral, but require partitions, with positive, zero, and negative parts for their symbolical expression. The author thus summarizes his results : (I) a simple proof of a generalized Vandermonde-Waring power law which presents itself in the guise of an invariantive property of a transcendental transformation; (2) the law of "groups of separations"; (3) the fundamental. law of algebraic reciprocity; (4) the fundamental law of algebraic expressibility which asserts that certain indicated symmetric functions can be exhibited as linear functions of the separations of any given partition ; $(5)$ the existence is established of a pair of symmetrical tables in association with every partition into positive, zero, and negative parts, of every number, positive, zero, or negative. - The closing portion of the number (pp. IO3-II4) is taken up with an article entitled "De l'Homographie en Mécanique," by P. Appell._A likeness of M. Poincaré faces p. I.-The index is of a twofold description-of authors and of subjects. From the forewords we learn that papers have been published from eighty-nine contributors; these comprise "most of the leading mathematicians of the world."

\section{SOCIETIES AND ACADEMIES. PARIS.}

Academy of Sciences, November Ir.-M. Hermite in the chair.-Presentation of Report of Proceedings of the permanent International Committee for preparing a photographic chart of the heavens, by M. E. Mouchez. Fifteen Observatories will be ready by the middle of next year; and five others before the end. The zones are indicated. - Note of M. Daubrée with descriptive catalogue of the meteorites of Mexico prepared by M. Antonio del Castillo. Meteorites are abundant in Mexico. A remarkably wide area of dispersion is indicated by three portions of one mass, found at the angles of a triangle, whose two longer sides were $90 \mathrm{~km}$. and $60 \mathrm{~km}$. In one of these places two plates were found $250 \mathrm{~m}$. apart ; and they seem to have formed one huge plate over $24,000 \mathrm{kgm}$. weight, which broke near the ground. On the incineration of vegetable matters, by M. G. Lechartier. Trying various methods, he finds, that in the carbonization and incineration of a plant, there is considerable loss of sulphur, volatilized in various combinations; and special precautions are necessary in determining this constituent. Under the same conditions, and care being taken to prevent loss of solid matter carried away mechanically with the issuing gas, there is no sensible loss of phosphorus.-M. Picard was elected member in Geometry, in place of the late $M$. Halphen.-On a rotating magnetic field formed with two Ruhmkorff coils, by M. W. De Fonvielle. A current from accumulators is sent through the primary of one coil, the secondary of which is connected with that of the other coil, which is in a line with the first, and the primary of which may be open or closed. - On certain ellipsoidal areas, by M. G. Humbert.-On a new calculating machine, by M. L. Bollée. While in previous machines, multiplications, e.g., are done by successive additions, this one has a multiplying apparatus which determines immediately, in one function, the product of a number by each figure of the multiplier. - On the solubility of the chlorides of potassium and of sodium in the same solution, by M. Étard. The results of experiment are shown in graphic form; the curves of solubility of each salt separately being compared with those of the mixed salts, \&c. The sum of the dissolved salts is represented by a continuous straight line. The curves for the mixed salts cross at temperature $97^{\circ}$; that for $\mathrm{NaCl}$ falling while the other rises.-On an application of thermo-chemistry, by M. A. 